\title{
Ilustración, cahiers, rapports (1730-1799) Apuntes sobre los orígenes de la educación pública contemporánea
}

\begin{abstract}
«Con el movimiento iluminista, escuela y educación se constituyen en objeto de enfrentamiento ideológico y de lucha política. Y esto en unos términos que resultan muy fáciles de reconocer actualmente. No en vano se sabe que, en no importa qué campo, el pensamiento contemporáneo es heredado de la gran corriente ilustrada, cuyas figuras más significativas son, asimismo, fáciles de identificar: por de pronto, Condorcet, D'Alambert, Voltaire, Montesquieu, Rousseau. Como conjunto, estos pensadores entre otros representan la respuesta ideológica coherente a la crisis abierta por la sociedad del antiguo régimen. Esta crisis, como es también sabido, encuentra su desembocadura en la revolución francesa y en la revolución industrial, en cuyo contexto, y come si se tratase de un verdadero período constituyente, se estructuran las grandes corrientes del pensamiento contemporáneo, desde el liberalismo al socialismo utópico, desde la filosofía idealista al marxismo, pasando por la sociología positiva» (p. 47).
\end{abstract}

"Cuando termina el siglo, tanto en el campo de las ideologías pedagógicas, como en el de la política escolar, casi todo lo esencial se ha dicho, y casi todo lo significativo ha sucedido ya. Básicamente, con esos materiales ideológicos es con los que trabaja todo el siglo diecinueve. Dentro del ámbito de las concepciones educativas, se asiste a los intentos de revalorización de la escuela del trabajo (socialismo utópico) y, fundamentalmente, a una vuelta, pura y simple, a Rousseau. Con una importante novedad: la aparición de la sociología positiva de la educación. Por otra parte, la política escolar gira en torno a las realizaciones de la revolución francesa, y en nuestro país en torno a los proyectos de las Cortes de Cádiz» (p. 65).

(Lerena, Carlos: «Escuela e llustración: la doble raíz de las teorías de la educación contemporánea", en Materiales de sociología de la educación y de la cultura. Madrid, Zero, 1985, pp. 47-66).

\section{Dos citas}

He aquí las raíces históricas del pensamiento sociológico de Carlos Lerena. Se encuentran en una parte del enunciado de nuestro trabajo y pueden tener una primera expresión en esas dos citas. La primera, sobre la llustración y su significado histórico. La segunda, sobre el programa histórico-pedagógico del siglo XIX, en tanto que materialización de las ideas ilustradas y revolucionarias. 
El positivismo y el socialismo utópico perfilan aún más, histórico-genéticamente, el pensamiento de nuestro homenajeado. En particular, Durkheim y Saint-Simon. Vendrá luego la influencia honda y definitiva de Marx. En otra y distinta medida, Freud. Y, más recientemente, Foucault y Bourdieu. Esta es la razón -en el 1ำ sentido rousseauniano- de Carlos Lerena. Su sentimiento, en cambio, estaba en Berceo. En Berceo y en Gonzalo de Berceo; en su lectura bastante durkheimniana de nuestra Edad Media y, sobre todo, en el mensaje explícito y oculto -que se fue adensando más y más con el tiempo- de la literatura española medieval. Literatura vista y estudiada por él cada vez más de cerca. Reprimir y liberar era ya, en parte, una primera síntesis. El binomio educación/cultura estaba en el centro de sus preocupaciones. Por ahí debería haber caminado su nueva obra...

\section{Los origenes}

Parece evidente que los orígenes textuales de la educación pública contemporánea están en los Rapports. Pero los orígenes teóricos estaban ya en Platón. A través de su filosofía de la polis, Platón descubre la importancia de la educación para el buen funcionamiento del Estado. En La República esboza un modelo de inserción del sistema educativo en la estructura del Estado. Será él quien logre entender primero el carácter reproductor de la educación y el primero en concluir que la educación actúa como elemento perpetuador de determinados valores e intereses sociales. A partir de entonces, podrá hablarse ya de la educación como una cuestión de Estado...

Y si los orígenes teóricos de la educación pública están en la Atenas clásica, los institucionales se encuentran en las prácticas escolares medievales, como muy bien señala Durkheim ${ }^{1}$. Es aquí donde la educación se convierte en sistema, aunque no se trate precisamente de un sistema al servicio del Estado, sino al servicio de la superestructura política dominante en la Edad Media: La Iglesia².

Por su parte, y a partir de 1730 aproximadamente, el movimiento de la llustración construirá la teoría textual de lo que será la educación pública contemporánea en las sociedades capitalistas. Poco después, los Cahiers de doléances de la Asamblea Nacional se convertirán en la expresión más desgarradora de las necesidades populares que ya habían sido apuntadas por los ilustrados. Por último, y en particular entre 1789 y 1794, los

1 DURKHEIM, E.: Historia de la educación y de las doctrinas pedagógicas. Madrid, La Piqueta, 1982, pp. 56-59. 2 ALTHUSSER, Louis, en su célebre artículo «El apartado ideológico escolar del Estado como aparato dominante», se referirá, en este caso, a la Iglesia como «aparato ideológico». Mariano Fernández Enguita establecerá una corrección al discurso althusseriano, señalando que también producen ideología «las relaciones de producción y cambio, invertidas en la realidad» (Véase "La escuela y la socialización para el trabajo", en $I$ Simposium sobre el proceso de socialización. Ponencias y comunicaciones. Universidad de Santiago, 1988, pp. 145-161). En cualquier caso, parece obvio que es entonces cuando la educación se constituye definitivamente como sistema, con unas funciones claras de inculcación ideológica y de reproducción de las condiciones de producción. Julia Varela hablará de modos de educación (Cfr. Julia VARELA: Modos de educación en la España de la Contrarreforma. Madrid, La Piqueta, 1984). Los planteamientos de la socióloga de Chantada y su análisis detallado nos llevarían ahora demasiado lejos. 
Rapports vendrán a ser la síntesis práctica más llamativa que recoge esa teoría y esas necesidades.

Es completamente secundario que los Rapports caigan a veces en las utopías más desarofadas. Históricamente, importa mucho más el trasfondo que reflejan que lo que realmente dicen. La lectura utópica de los Rapports que hace por ejemplo Bronislaw Baczko ${ }^{3}$ es puro diversionismo. Porque no siempre interesa el mensaje explícito, sino el contenido latente, la actitud, el espíritu. Y está claro que, con los Rapports, la educación se consagra como un aparato ideológico del Estado de primer orden, como un poder auténtico, que dirá Talleyrand. La educación es ya un medio insustituible de reproducción de las estructuras de los Estados contemporáneos.

La educación conserva también otra dimensión: reproduce, cierto, pero produce a un tiempo. La educación es producción, saber, creación de cultura, capacidad transformadora. André Petitat, en un trabajo de $1982^{4}$, afirma que las teorías sociológicas reproductoras dan cuenta de realidades importantes, pero son incapaces de explicar el movimiento histórico en su conjunto. Según ellas - dicen- «la enseñanza se presenta siempre como un freno, una fuerza de conservación, un obstáculo al cambio. La evolución se produce a pesar del sistema de enseñanza. Ahora bien, tal afirmación contiene sólo una parte de la verdad. La realidad es contradictoria y. múltiple. Por una parte, la escuela reproduce y, por otra, alimenta el movimiento que trata de abolir la situación existente» 5 .

Más adelante, añade:

«En suivant ce cheminement, mon travail s'est alors orienté vers une remise en cause explicite des théories de la reproduction en éducation. Ces théories restent muettes devant le mouvement de l'histoire, même si leurs problématiques sont incompréhensibles en dehors de lui. L'école ne participe-t-elle pas en permanence à la définition de nouvelles distinctions culturelles? A chaque révolution religieuse ou politique, $n$ 'a-t-elle pas diffusé et étendue les nouveaux credos? A l'occasion, et contre toute attente, n'a-t-elle pas trahi la confianse que ses dirigeants fondaient en elle? Comment peut-on faire abstraction de l'école dans l'unification culturelle et linguistique des Etats-nations? L'écriture, instrument de domination, généralisée par l'école d'Etat, n'a-t-elle pas joué un rôle important dans la formation et la diffusion d'une conscience de classe parmi les nouveux prolétaires de la révolution industrielle?

3 BACZKO, B.: Une éducation pour la démocratie. Textes et projets de I 'époque révolutionnaire. Paris, Gamier, 1982. Además de la antología de Baczko, una edición más completa, sin ser exhaustiva, de los Rapports es la de HIPPEAU, C.: L 'instruction publique en France pendant la Révolution. Paris, Didier et Cie. Libraires-Editeurs, 1881.

4 PETITAT, A: Production de l'école-Production de la société. Analyse socio-historique dequelques moments décisifs de l'évolution scolaire en Occident. Geneve, Droz, 1982

5 Ibidem, p. 12.

6 Ibidem, p.13 [ siguiendo esta orientación mi trabajo se convirtió en un cuestionamiento explícito de las teorías de la reproducción en educación. Estas teorías permanecen mudas ante el movimiento de la historia, incluso si sus problemáticas son incomprensibles al margen de ellas. ¿Acaso la escuela no participa permanentemente en la definición de nuevas distinciones culturales? ¿Acaso no ha difundido y extendido las nuevas doctrinas en cada 
Petitat plantea aquí, en otros téminos, el esquema de funcionamiento de la lucha de clases en el interior mismo del sistema educativo. 0 , si se quiere, aborda el viejo tema de la doble dimensionalidad del fenómeno educativo: a) la educación como saber, como "práctica técnica», como creación cultural —técnica y ciencia-, y b) la educación como «práctica social», como sistema y como reproducción —ideología—?.

\section{Ilustracion/Revolucion}

La llustración es la razón necesaria, pero no suficiente de la Revolución de 1789, dijo un día Pierre Vilar. Sin la teoría política y pedagógica de los ilustrados, la Revolución no hubiera sido posible. Existe una íntima relación dialéctica entre los textos de Montesquieu, Voltaire, Rousseau, Diderot, Helvétius, D'Holbach, los Cahiers de doléances de 1789 y los Rapports de 1789-1799, si pensamos sobre todo en la revolución que se produce en el ámbito de la educación.

Ese grupo de intelectuales modernos que son los ilustrados franceses, en tanto que abanderados de una clase burguesa con poder económico y en ascenso social imparable, van a preparar un nuevo modelo teórico-práctico de Estado, un Estado de nuevo tipo; en definitiva, el Estado que necesita la burguesía. Será Montesquieu el primer arquitecto que trabaje en la construcción de ese Estado. A él le corresponde, partiendo de Locke, la cimentación y el diseño de la estructura del gran edificio. El Espíritu de las leyes es el armazón de ese nuevo Estado y el anuncio de la caída del Estado esclerotizado del Antiguo Régimen.

Es claro, como decíamos, que la llustración no es razón suficiente para esa revolución que abre la época contemporánea. En el fondo, estaban las razones económicas y sociales, las condiciones objetivas que la propiciaron: la explosión demográfica del XVIII, el crecimiento de las ciudades, la crisis ideológica de la Iglesia y sus relaciones corruptas con el viejo Estado, etc. No obstante, son los ilustrados quienes elaboran el diseño teórico de ese proceso, la teoría que se necesitaba para la acción política deseada por todo el Tercer Estado.

Se trataba, pues, de perfilar un nuevo Estado (Montesquieu), con una organización política de nuevo tipo (Voltaire, Diderot, Rousseau), con una educación y una cultura nuevas (Diderot, Rousseau, Helvétius, D'Holbach y, más tarde, Condorcet y Talleyrand) y del que surgiría un nuevo tipo de ciudadano y un hombre nuevo (Diderot, Rousseau).

\footnotetext{
revolución religiosa o política? Y en este caso, ¿no ha traicionado, contra lo que se esperaba, la confianza que sus dirigentes depositaban en ella? ¿Cómo se puede hacer abstracción de la escuela en la unificación cultural y lingüística de los Estados-nación? ¿Acaso la escritura, como instrumento de dominación generalizado por la Escuela del Estado, no ha jugado un papel importante en la formación y la difusión de una conciencia de clase entre los nuevos proletarios de la revolución industrial?]

7 A propósito de la doble dimensionalidad científica e ideológica de la educación, y en el contexto de las relaciones ciencias sociales/ideología, es bueno remitir al lector a un viejo pero clarividente y magistral trabajo de SANCHEZ VAZQUEZ, Adolfo: "La ideología de la "neutralidad ideológica" en las ciencias sociales", en Zona Abierta, n. ${ }^{\circ} 7,1976$.
} 
Con este esquema, los ilustrados generan toda una revolución teórica utilizando las armas de la crítica filosófica, científica, política e ideológica. Crítica multiforme y polifacética basada en la teoría del progreso social y en el uso de la razón como método de análisis de la realidad. Esa crítica omnia de los ilustrados, su actitud de subversión radical de la concepción del mundo dominante y el sello de philosophes que se imponen, darán lugar al nacimiento de una nueva conciencia social, en determinados sectores de la sociedad, que hará irreversible el proceso histórico que se avecina.

Asistimos así al nacimiento de la primera conciencia contemporánea de lo que será la educación pública. Se trataría de construir un sistema educativo adecuado a las necesidades que se prevén para el nuevo Estado. En definitiva, un sistema educativo al servicio del nuevo Estado. Los ilustrados van tomando progresivamente conciencia de la importancia capital de la educación para la implantación y mantenimiento del Estado burgués que querían poner en pie. Y llegarán a concluir incluso que no hay revolución política posible si no va acompañada de una revolución educativa paralela. Consideran a la educación como una palanca de transformación social de primer orden.

Rousseau, en el Emilio, elabora los principios de la educación nueva que el nuevo ciudadano del Estado nuevo necesitaba. Con esa educación creía Rousseau que encontraríamos al fin al hombre universal, al hombre reconciliado con su verdadera naturaleza y renacido de su historia auténtica. El concepto clave que utiliza Rousseau en su trabajo será el concepto de libertad: libertad natural, civil y moral, en tres estadios progresivos en los que la libertad se perfecciona sucesivamente y que responden a una concepción de la Historia y del Estado esbozados pormenorizadamente en el Discurso y en el Contrato. Libertad no en cuanto "conciencia de la necesidad» como dirá Engels, sino en un sentido igualitarista y pequeño-burgués ${ }^{8}$. Libertad para hacerse con una propiedad... (Más tarde, libertad de empresa, libertad de enseñanza...). A partir de 1789: libertad, igualdad, fraternidad. Poco después, igualad, libertad, fraternidad... En este orden. Porque sin igualdad no puede haber auténtica libertad. Y porque sin una libertad de iguales es imposible la fraternidad (socialistas utópicos, Marx).

En la práctica, La Chalotais aborda la reforma del sistema educativo en su Ensayo de educación nacional, obra que Voltaire saluda con alborozo y que aparece sólo un año después del Emilio (en 1763). Y Helvétius llega más lejos que ellos a la hora de considerar a la educación como asunto de Estado. Para Helvétius \{De L'Esprit), no es únicamente una cuestión fundamental de Estado, sino que la educación debe figurar en la Constitución. Es ya más que un servicio. Es un derecho constitucional ${ }^{9}$. Y debe serlo porque, para Helvétius (y también para Rousseau), «todo lo que no recibamos al nacer, se lo debemos a la educación». En un análisis típicamente mecanicista, para Helvétius, "educación» es sinónimo de "circunstancias». Su punto de partida es maximalista y reduccionista a un

8 Sobre este aspecto del pensamiento de Rousseau, vid. DELLA VOLPE, G.: Rousseau y Marx. Barcelona, Martínez Roca, 1975, pp. 13-100.

9 Lorenzo LUZURIAGA, en abril de 1931, publicará un artículo en la Revista de Pedagogía que se titulará precisamente, «Ideas para una reforma constitucional de la educación pública» 
tiempo, pero tiene un efecto muy sano y liberador en aquel momento: objetivamente se oponía a la sacrosanta desigualdad consagrada por la Iglesia. Para Helvétius todos «nacemos iguales». Luego, las desigualdades sociales, nacionales, culturales, sexuales, etc., son el producto de una educación discriminatoria e injusta. Por eso, «la formación del hombre está tan estrechamente ligada a la forma de gobierno, que no es posible hacer ningún cambio importante en la educación pública si no se cambia también la constitución misma de los Estados ${ }^{10}$.

Diderot, el gran trabajador, el organizador, ei hombre polifacético de la llustración, es también el hombre de las ciencias y de las nuevas letras críticas. El es el teórico de la cultura científica ilustrada, el gran animador de la Enciclopedia. Es la síntesis personificada del movimiento iluminista. Pondrá el acento en el carácter cívico y moral de la nueva educación pública y, sobre todo, en su papel de forjadora del nuevo «espíritu nacional» que se necesitaba. Espíritu que estaba en franca oposición con la atmósfera sectaria, confesional y privada de la «educación doméstica, religiosa y particular».

Las aportaciones de Rousseau, Helvétius y Diderot al análisis de las características y la función del fenómeno educativo, convierten a la educación en uno de los grandes protagonistas del movimiento de las luces. Para todos los ilustrados, el Estado será la máxima autoridad responsable en materia de educación. Según eso, el sistema educativo debe ser un sistema unificado y controlado por el Estado. Ello implica una centralización de la educación. Educación que deberá tener, además, un carácter público y opuesto a la privada. Pero decir «pública» quiere decir "colectiva». Y una educación "colectiva» no podrá ser otra cosa, en el nuevo Estado, sino «nacional».

\section{Los cahiers}

Durante el año 1789, los Estados Generales van recogiendo quejas en los cuadernos de sesiones. Los célebres Cahiers de doléances se convertirán así en fuente de primera mano para analizar las inquietudes políticas del momento, el cambio cualitativo que se observa en el concepto mismo de educación y, sobre todo, en el papel que ésta debería jugar en el nuevo Estado que se vislumbra.

Antoine León, en un viejo pero sustancioso trabajo de $1970^{11}$, traza un bosquejo del lugar que ocupa la pedagogía en los Cahiers. Más que un estudio en profundidad del significado histórico-pedagógico de los Cuadernos, se trata del enunciado de ciertos problemas de método a la hora de la crítica, de algunos extractos valiosos y de las tesis más importantes existentes hasta entonces en orden a su interpretación.

A su juicio, tres son las corrientes interpretativas principales: a) los Cahiers expresan opiniones comunes típicas del Antiguo Régimen ( $\mathrm{E}$. Allain); b) las doléances prefiguran el contenido de los proyectos revolucionarios (L. Bourrilly); c) los Cuadernos reflejan el

10 HELVETIUS: De L'Esprit. París, ed. sociales, 1968, p. 181

11 «La pédagogie au temps des révolutions», en Bulletin de Psychologie, 286, 1970, pp. 1082-1098. 
estado de ánimo colectivo típico de los años inmediatamente anteriores a la Revolución (D. Monet) ${ }^{12}$.

Esas tres corrientes sólo en apariencia pueden ser consideradas como antagónicas. Aunque, en realidad, la corriente b) es la que apunta directamente al sentido de la Historia y la que muestra la íntima relación de causa/efecto entre Ilustración/Cahiers/Rapports y, en general, la que explica la sucesión de acontecimientos de los procesos de escolarización del XIX, también es cierto que en los Cahiers se expresan opiniones típicas del Antiguo Régimen -a) - y se refleja el estado de ánimo colectivo de la época prerrevolucionaria -c). La distancia «teórica» entre el Ensayo de La Chaloíais (1763) y los Cahiers (1789) no es muy grande, pero la distancia práctica es enorme. Se estaba pasando de una teoría sin anclaje social concreto a la expresión de las más apremiantes necesidades populares 0 , en todo caso, a la expresión de ciertas necesidades de clase, en un momento en que la gran batalla se había puesto en marcha y era ya irreversible. Desde el 5 de mayo de 1789, los Estados Generales estaban en pie de guerra.

Los Cahiers son documentos históricos que recogen las vacilaciones políticas y la inestabilidad social del momento. Con el peso real del Antiguo Régimen en los talones, pero ya con el horizonte del Nuevo Régimen a la vista... Conviene subrayar lo que A. León también apunta en su artículo: sólo una pequeña parte de los Cuadernos está dedicada a cuestiones de política educativa. No debemos olvidar que «los Estados generales se reunieron, no para resolver un problema de educación (...), sino para poner fin al conflicto rey/aristrocracia» ${ }^{13}$. Aunque también es cierto que, día a día, los objetivos políticos de los Estados Generales se fueron ensanchando y radicalizando más y más.

Pero lo importante es que a la hora de dar salida «a las preocupaciones políticas, económicas y sociales más generales», se abordan "problemas de organización de la enseñanza» ${ }^{14}$. Esto quiere decir que, consciente 0 inconscientemente, la educación es ya considerada, en la práctica, como un instrumento político de primer orden.

Si nos atenemos a la cuantificación de fuentes disponibles, A. León apunta 1.240 cuadernos publicados integramente en los archivos parlamentarios, 1.103 extractos publicados por E. Allain y relacionados exclusivamente con cuestiones educativas, 417 extractos publicados por L. Bourrilly y consagrados también a esos problemas y una antología de textos publicada por P. Goubert ${ }^{15}$.

Los Cahiers son, por tanto, documentos históricos que recogen las inquietudes políticas y pedagógicas de un tiempo que se mueve entre la reforma y la revolución. En algunos

12 lbidem, p. 1090.

13 Ibidem.

14 Ibidem.

15 Ibidem, p. 1090. La bibliografía a la que Antoine León remite en su artículo comprende, entre otras, obras de ALLAIN, E.: La question d 'enseignement en France d 'après les Cahiers. Paris, Renouard, 1886; BOURRILLY L.. Les Cahiers de I 'instruction publique en 1789. Paris, Delograve, 1901; GOUBERT, P. y DENIS, M.: 1789. Les Français ont la parole. Paris, Julliard, 1964, y MORNET, D.: Les origines intellectuelles de la Révolution Française (1715- 1787). Paris, A. Collin, 1938. 
casos, atienden preferentemente a aspectos de simple mejora del sistema educativo. En otros, en cambio, evidencian una voluntad clara de transformar profundamente el sistema educativo. Como veremos, existe una considerable distancia teórica y práctica entre lo que expresan los Cuadernos de 1789 y lo que serán las iniciativas concretas de los legisladores de la Revolución. Esta ambigüedad de los Cahiers de doléances es una consecuencia directa de la inestabilidad del poder político y de los intereses contrapuestos de la Nobleza, el Clero y el Tercer Estado.

Parece, pues, evidente que, en vísperas de la Revolución, todavía no se plantea con claridad y decisión el tema de la generalización educativa. La opinión pública y los primeros representantes del pueblo tienen un cierto temor a una generalización de la enseñanza sin límites precisos. Lo más corriente es que se hable de una instrucción elemental y técnica para el pueblo y de una enseñanza secundaria y superior para los sectores sociales más influyentes. Es decir, más o menos en la línea del reformismo ilustrado de La Chalotais.

Los redactores de los Cuadernos oscilan, pues, como decíamos, entre la reforma y la revolución. En los textos parlamentarios, se contempla ya un diseño que anuncia la futura e inexorable división de lo que debería ser la escuela única. Lo que entonces era un paso adelante, se convertirá muy pronto en un paso atrás. Las dos redes de escolaridad estudiadas por Baudelot y Establet estaban ya presentes en el nacimiento mismo de la escuela contemporánea. La escuela contemporánea nacía, pues, como una escuela de clase. Era la anticipación de la unidad precaria y la falta de cohesión del Tercer Estado. La última vez que proletarios y burgueses iban a combatir juntos - dirá Marx — sería en el último acto de la Revolución: exactamente en 1848. 1871 será el epílogo de la Revolución burguesa y el prólogo de la Revolución socialista.

\section{La Revolucion. Los Rapports}

Será a partir del 14 de julio de 1789 cuando se empiece a hablar del problema educativo sin equívocos. Cada una de las clases sociales en liza va a defender encarnizadamente sus posiciones, presentando, sucesiva o simultáneamente, planes, programas, informes 0 anteproyectos de ley sobre educación, que serán acaloradamente discutidos. Como dice Lorenzo Luzuriaga, en su Historia de la Educación Pública ${ }^{16}$, "con la Revolución, la educación nacional francesa comienza a convertirse verdaderamente en algo práctico y operativo». El trabajo teórico de los ilustrados se convierte en práctica concreta y en una posibilidad histórica real.

Cada uno de los elementos culminantes del proceso revolucionario (Asamblea Constituyente, Asamblea Legislativa, Convención, Directorio, época napoleónica) trata de llevar a la práctica sus ideas sobre la educa ción nacional. Figuras clave que intervienen, en esos momentos, en asuntos educativos serán, entre otros, Mirabeau, Talleyrand, Condorcet, Romme, Lepeletier. Y, en casi todos los casos, su éxito no será inmediato, pero sus aportaciones serán irreversibles. Francia tendrá muy pronto un «sistema estatal de educación

16 LUZURIAGA, L.: Historia de la educación pública. Buenos Aires, Losada, 1964, cuarta edición, p. 47 y ss. 
nacional», tal y como habían soñado los ilustrados, aunque con las inevitables correciones introducidas por la historia real de los acontecimientos.

En su obra Lire et écrire, Furet y Ozouf sostienen una tesis a contracorriente. Afirman que la Revolución francesa, en contra de lo que se piensa, no ha significado un salto cualitativo espectacular en la alfabetización y escolarización de los franceses. Argumentan su posición en base al análisis comparativo - muy minucioso y documentado- de la situación revolucionaria con la alfabetización y escolarización del Antiguo Régimen. Hasta aquí no habría nada que objetar. Lo erróneo de la tesis de Furet y Ozout radica justamente en la elección del subsistema educativo primario como elemento pedagógico angular del proceso revolucionario.

No es en la primaria donde reside la importancia de los cambios, sino en la secundaria y en la superior. La preocupación de la burguesía finisecular, siguiendo los preceptos de los ilustrados que se preocupaban en particular de la educación como cuestión de Estado, se centrará en la formación de élites dirigentes cualificadas. Napoleón recoge ese mandato de clase y se propone como objetivo principal la constitución de una importantísima red de Lycées y la reorganización total de las Universidades. La primaria —la educación popular - será la gran batalla del XIX, con Pestalozzi al principio y Férry al final de la centuria. Todavía era pronto para lograr la unificación de todos los subsistemas educativos. El Estado recién formado tenía que elegir y conceder prioridades y sus intereses de clase eran claros y reflejaban con precisión la correlación de fuerzas en el país. La educación, sin duda, empezaba a ser ya un gran aparato...

Bronislaw Baczko, en la obra ya citada, hace, como decíamos al principio, una lectura utópica de los Rapports. Se empeña en analizar lo desmesurado de sus objetivos, su carácter utópico clásico, cuando, en realidad, debería haber reparado más, mucho más, en lo que los Rapports anuncian... Porque los Informes revolucionarios serán los textos sobre los que se va a discutir durante más de cien años en la Historia de la Educación. No interesa, pues, en absoluto, situarlos en el tiempo breve y concreto en que se producen. Al contrario, deben ser proyectados en el ancho futuro en que darán todos sus frutos. La escuela de hoy, o mejor, el sistema educativo actual de los países capitalistas no es más que una variante de los Rapports ${ }^{17}$, recortados en su dimensión revolucionaria inmediata y troceados en virtud de los procesos históricos ulteriores, en los que la burguesía y las clases dominantes se atrincheraron en el poder y pretendieron por todos los medios frenar el despliegue liberador y las potencialidades creativas que contenían. Y eso no es utopía, sino corrección histórica en función de los intereses de clase. Lo «utópico» ya no lo es tanto en el transcurso de los procesos revolucionarios socialistas contemporáneos.

En su libro Une éducation pour la démocratie, el profesor Baczko se limita a una introducción, con el análisis de fondo que acabamos de apuntar. Es una revisión de la Revolución francesa en su vertiente pedagógica —o mejor, escolar-, en la línea de la obra de Furet/Ozouf. Revisión, en mi opinión, típicamente academicista y excesivamente centrada

17 Vid. BACZKO, B.: Op. cit., p. 69. 
en ios problemas de la alfabetización y la escolarización primaria. La misma antología de Rapports - incompletos - que nos presenta resulta demasiado sesgada. Y aún así es perfectamente posible hacer una lectura muy distinta de su misma muestra antològica.

Existen demasiados indicios de que la antología de Baczko es un intento más de desactivar los efectos de la Revolución francesa, de minimizarla o incluso de negarla. Bajo el pretexto de la desmitificación, se esconde la reacción. De la misma forma que Furet ataca frontalmente el carácter de la Revolución en Pensar la Revolución francesa, Baczko hace lo propio con los grandes proyectos educativos de 1789-1799. Toma por utopía aquello que la burguesía no quiso poner en práctica, sencillamente porque iba contra sus intereses.

De Mirabeau (1749-1791) nos quedan algunas notas de discursos importantes. En uno de esos discursos [Sobre la Instrucción Pública y la organización del cuerpo de enseñanza], Mirabeau defiende el principio de la libertad de enseñanza. A partir de entonces, éste será ya un tema recurrente en la Historia contemporánea de la educación pública y estará en boca de los principales artífices de las políticas educativas de nuestro tiempo, aunque con las intenciones más diversas. El discurso de Mirabeau a que aludimos es una dura diatriba contra el Estado del Antiguo Régimen.

En un primer momento, Mirabeau —un reformista - no es partidario del intervencionismo absoluto del Estado en cuestiones educativas. Pero, a pesar de sus reservas teóricas y de principios, y teniendo en cuenta el estado lamentable de la educación privada, cree que la Asamblea debería elaborar un proyecto de organización de la enseñanza pública que garantice una efectiva libertad de enseñanza.

Teniendo en cuenta la situación política del momento, para Mirabeau, sólo el Estado podía garantizar esa libertad. Considera que hay que poner en marcha un plan «para comprometer a los maestros en la nueva tarea y que sea capaz de apoderarse del espíritu de la juventud» ${ }^{18}$. Tendrá que ser la Asamblea la que decida qué escuelas serán sostenidas y fomentadas por el Estado y qué tipo de instrucción deberán seguir en ellas los alumnos.

Por su parte, Talleyrand (1758-1838) es autor de un Rapport sur l'Instruction publique, presentado en la Asamblea en 1791. En él, Talleyrand considera a la educación como un poder, puesto que actúa: 1) sobre el perfeccionamiento del «cuerpo político» y 2) sobre la «prosperidad general». Momento históricamente importantísimo y consideración cualitativamente nueva de la educación. Al ser entendida como un poder, la educación se convierte objetivamente en un aparato del Estado. Su incidencia en el perfeccionamiento del "cuerpo político" la transforma en un excepcional vehículo transmisor e inculcador de ideología. Por otra parte, la influencia de la educación en la «prosperidad general» pone sobre el tapete el tema capital de su acción directa en la economía y en el sistema productivo. Quedan así planteadas en la práctica las correlaciones sistema político/sistema educativo y sistema educativo/sistema productivo.

Pero, oigamos al propio Talleyrand:

18 LUZURIAGA, L.: Op. cit, p. 50. 
«Les pouvoirs publics sont organisés: la liberté, l'égalité existent sous la garde toutepuissante des lois; la propriété a retrouvé ses véritables bases; et pourtant la Constitution pourrait sembler incomplète, si l'on $n$ 'y attachait enfin, comme partie conservatrice et vivifiante, l'instruction publique, que sans doute on aurait le droit d'appeler un pouvoir [cursiva en el texto], puisque'elle embrasse un ordre de fonctions distinctes qui doivent agir sans relâche sur le perfectionnement du corps politique et sur la prospérité générale». ${ }^{19}$

Para Talleyrand, la educación es, además, pieza importantísima para la feliz implantación de la nueva Constitución, como ya significara Helvétius y como recogerán más tarde muchos pedagogos del XIX y del XX. «La instrucción — dice- ensancha la libertad civil y ésta, a su vez, la libertad política». Y la libertad política «impide la aparición del despotismo ${ }^{20}$.

La única instrucción que el Estado debe ofrecer con la mayor gratuidad (repárese en el posibilismo) «es la esencialmente común a todos, por ser necesaria para todos» ${ }^{21}$. Se trata, evidentemente, de la educación elemental tal y como sería entendida por las burguesías nacionales de nuestra época. La finalidad esencial de esa educación es "enseñar a los niños a que lleguen a ser un día buenos ciudadanos " ${ }^{22}$. Coincidencia total con las concepciones expuestas por Diderot en su Plan de una Universidad para el gobierno de Rusia. Diderot llamaba aquí la atención sobre el papel de la educación como agente principal del cambio de mentalidad y sobre su función de ajuste entre lo que él llamaba «ley natural» y «ley civil», indispensable para el buen funcionamiento de la sociedad y del Estado. Sólo que aquí, Talleyrand, consciente de los recursos aún limitados del nuevo Estado, cree que la educación debe ofrecerse, pero no «imponerse». Esa «imposición» implicaría la gratuidad y la obligatoriedad y este nuevo "salto" en la evolución del sistema educativo sólo se produciría «teóricamente» con el Rapport Condorcet. Talleyrand interpreta todavía la educación como un servicio, pero no como un derecho, aunque ya dejara de ser un privilegio.. (En realidad, habría que recorrer aún un largo camino...).

Sobre el carácter constitucional de la Instrucción Pública ${ }^{23}$, dice Talleyrand:

«La première instruction serait placée dans chaqué canton, ou, plus exactement, dans chaqué division qui renferme une assemblée primaire (...)

...II faut que l'instruction s'allie le plus possible au nouvel état des choses, et qu'elle présente, dans ces diverses gradations, des rapports avec la nouvelle Constitution [cursiva nuestra]» ${ }^{24}$.

19 BACZKO, B.: Op.cit.,p.109 [Los poderes públicos están organizados: la libertad, la igualdad existen bajo la vigilancia todopoderosa de las leyes; la propiedad ha encontrado de nuevo sus verdaderas bases; sin embargo, la constitución podría quedar incompleta, si no se le añade, como parte conservadora y vivificante, la instrucción pública, a la que sin duda debemos llamar un poder, ya que abarca un orden de funciones distintas que deben actuar constantemente en el perfecccionamiento del cuerpo político y en la prosperidad general]

20 Cit. por LUZURIAGA: ibídem, pp. 50-51.

21 Ibídem, p. 51.

22 Ibídem.

23 Véase HELVETIUS: Op. cit, passim, y LUZURIAGA, L. nota 9.

24 BACZKO, B.: op. cit., p. 119. 
Parece fuera de toda duda que las cinco Memorias de Condorcet sobre educación y, particularmente, su Rapport et projet de décret sur l'organisation générale de l'instruction publique (abril-diciembre, 1792) son el elemento definitivo que catapulta a la educación como tarea primordial del nuevo Estado y que la convierte en palanca de transformación social de primer orden. Desde ese momento, los políticos saben ya que no puede haber revolución política posible si no va acompañada de una revolución educativa paralela. El Rapport Condorcet vendrá a ser el alfa y el omega de toda reforma educativa importante y el punto de referencia inevitable de las políticas educativas que se pondrán en marcha a lo largo del XIX y aún en el primer tercio del XX.

Para Condorcet, la educación significa: 1) ofrecer a todos los individuos los medios de proveer a sus necesidades; 2) asegurar el bienestar; 3) conocer y ejercer sus derechos y comprender y cumplir sus deberes; 4) capacitar y cualificar al individuo para el desarrollo de sus capacidades naturales y garantizar la igualdad de hecho entre los ciudadanos. He aquí el resumen más expresivo del programa educativo de la burguesía a lo largo del siglo XIX. Como dice Carlos Lerena, en la segunda cita que encabeza este trabajo, «cuando termina el siglo, tanto en el campo de las ideologías pedagógicas, como en el de la política escolar, casi todo lo esencial se ha dicho, y casi todo lo significativo ha sucedido ya. Básicamente, con esos materiales ideológicos es con los que trabaja todo el siglo diecinueve». Condorcet da un paso más que Talleyrand. La instrucción pública es un deber de justicia para los poderes públicos. Elabora después un detallado programa educativo en el que introduce con claridad el principio del laicismo. Cree necesario separar la moral -ética civil- de los dogmas religiosos. La moral religiosa debe ser sustituida por la moral civil. Jules Férry libraría, en Francia, la batalla decisiva por el laicismo.

Esta nueva forma de la conciencia social, a la que contribuyó de manera decisiva Condorcet, dará lugar a que se imponga paulatinamente una nueva mentalidad en el pueblo francés. Y esa nueva mentalidad se deberá, en buena medida, a la presencia creciente de la instruction civique en los establecimientos escolares. Se producirá así un giro radical en lo que Louis Althusser denominará las ideologías prácticas.

En el Informe de Condorcet, las ciencias ocupan el lugar preeminente que ocupaban las letras. La cultura científica era considerada ya, en amplios círculos-la aportación ilustrada había sido fundamental-, como la cultura de vanguardia. Es un adelanto de lo que será el positivismo. También aquí, Condorcet resume y sintetiza las aspiraciones de la burguesía: espíritu científico, positivo y práctico.

Libertad de conciencia, libertad de enseñanza; libertad de doctrinas. Trinidad burguesa y rousseauniana que desarrolla Condorcet. Libertad de conciencia para poder combatir la religión. Libertad de enseñanza porque el Estado no tiene todavía los medios de subvenir a las necesidades sociales en materia de educación ni era «todavía» el Estado que pretendía la burguesía, libertad de doctrinas para que desaparezcan las trabas que se oponen al progreso científico. Como se ve, efectivamente, aquí ya está casi todo... 
G. Romme, en su Rapport sur l'instruction publique, presentado por Lanthenas en la Convención, en diciembre de 1792, retoma las ideas de Condorcet, «acentuando sin embargo su orientación laica» ${ }^{25}$ y, desviándose de la línea condorcetiana, trata de aprovechar la coyuntura política, tan agitada, de aquel final de año, para modificar algunos aspectos importantes del Rapport Condorcet. Al mismo tiempo, el diputado Romme se interna en su Informe en toda una serie de consideraciones teóricas sobre los conceptos de instrucción y educación. Ello era prueba indudable de que el pensamiento político-educativo se había ido adensando en los últimos tiempos y, en esta nueva fase de la Revolución, cerca ya de su momento álgido, la instrucción pública (o, lo que es lo mismo, la educación como asunto vital para el Estado) era un tema apasionante y absorbente para los diputados de la Convención.

Véase el enfoque de G. Romme a través de estas citas sueltas, correspondientes a la Seconde Question de su Informe y bajo el epígrafe Que doit être l'instruction publique?, a propósito de instrucción y educación:

«L'instruction éclaire l'esprit, exerce toutes les facultés intellectuelles, étend la domaine de la pensée.

L'éducation développe le caractère, imprime à l'àme una impulsion salutaire, dirige la volonté...

L'instruction recueille les fruits de l'experience et des méditations...

L'éducation en fait un choix...

L'instruction, sans léducation, donne les talents et de l'orgueil, des moyens et de la jactance...

L'éducation sans l' instruction ne peut former que des habitudes et conduire à tous les préjugés...» (Cursiva nuestra) ${ }^{26}$.

El 13 de julio de 1793. Maximilien Robespierre presenta en la Convención Nacional el Plan d 'éducation nationale de Lepeletier. En su discurso, Robespierre dijo, entre otras cosas:

«Avec la mémoire de ses vertus, Michel Lepeletier a légué à la patrie un plan d'éducation publique, que le génie de l'humanité semble avoir tracé»27.

El Plan de Lepeletier es considerado como la obra más radical y audaz de los Rapports sobre educación debatidos en Francira durante este período revolucionario. Luzuriaga afirma al respecto:

«El proyecto es una mezcla de ideas utópicas, inspiradas en la educación espartana y de ideas originales, entre ellas, por primera vez, la de la obligación escolar ${ }^{28}$.

El Plan de Lepeletier es quizá el trabajo más profundo de los presentados a debate. A pesar del contenido utópico que en él late — tal y como subrayan Luzuriaga y Baczko-,

25 BACZKO, B.: Ibidem, p. 263. Bronislaw Baczko nos proporciona una detallada Notice de cada uno de los autores de los Rapports.

26 Ibidem, p. 272.

27 Ibidem, p. 347.

28 LUZURIAGA, L.: op. cit., p. 55 
lleva muy lejos los objetivos revolucionarios en materia educativa y sintetiza espléndidamente lo mejor de las teorías existentes de tipo pedagógico y el proyecto político jacobino. He aquí algunas muestras:

"La Convention nationale doit trois monuments à l'histoire: la constitution, le code des lois civiles, l'éducation publique» (p. 348).

«Former des hommes, propager les connaissances humaines; telles sont les deux parties du problème que nous avons a résoudre. La première constitue l'éducation, la seconde, l'instruction" (p. 348).

«Prolonger l'instruction publique jusqu'à l'adolescence est un beau songe; quelquefois nous l'avons rêvé délicieusement avec Platon; quelquefois nous l'avons lu avec enthousiasme, réalisé dans les fastes de Lacédémone: quelquefois nous en avons rétrouvé l'insipide caricature dans nos collèges"...(p. 353) ${ }^{29}$.

Están presentes, en las citas anteriores, los problemas más agudos y serios de la educación revolucionaria: la relación constitución/legislación/educación pública, la distinción educación/instrucción ${ }^{30}$ y la necesidad política de la generalización educativa.

Ilustración, Cahiers y Rapports son, pues, los elementos angulares para la constitución de los sistemas educativos contemporáneos. Sin ellos, la educación pública de nuestros días no puede ser entendida ni explicada.

(Publicado en Sociedad, Cultura y Educación. Homenaje a la memoria de Carlos Lerena Alesón; Madrid, Centro de Investigación y Documentación Educativa, Universidad Complutense, 1991, pp.155-170.)

29 BACZKO, B.: Op. cit., pp. 348-353.

30 En un trabajo conjunto con Narciso de Gabriel, en fase de preparación, ahondamos en esta distinción, así como también en otros aspectos importantes de los Rapports. En él, tratamos de hacer un análisis de contenido y de la proyección histórica de los Informes, abordando igualmente las consecuencias de las reformas educativas napoleónicas. 